\title{
Integration of Activity-Based Costing Modifications and LEAN Accounting into Full Cost Calculation
}

\author{
Neringa Stonciuviene, Ruta Usaite-Duonieliene, Danute Zinkeviciene
}

Vytautas Magnus University

K. Donelaicio st. 58, LT-44248, Kaunas, Lithuania

E-mail.neringa.stonciuviene@vdu.lt,ruta.finance@gmail.com,danute.zinkeviciene@vdu.lt

cross $^{\text {ref }}$ http://dx.doi.org/10.5755/j01.ee.31.1.23750

\begin{abstract}
The purpose of this research is to design a production company fitted full product cost calculation model following analysis of Activity Based Costing (ABC), its modifications and LEAN accounting system principles. The study is based on analysis and comparison in ABC, Time Driven Activity Based Costing (TDABC), Service-Based Costing (S-BC), Duration Based Costing (DBC) and LEAN accounting. The designed innovative full product cost calculation model integrates the following management system elements: LEAN value streams, ABC activities, TDABC time driver, S-BC customer rating, and DBC production duration factor, and has been adapted to a company producing large and complex unique articles. Applicability analysis of the model has involved data systematization, grouping, collection of additional data under the interview method, data interpretation, summarisation, logical conclusion making. Applicability of this model and more efficient control of the pricing decisions at the company, ensuring its greater competitive ability, have been justified by financial calculations. In formation of the full cost calculation model, both the quantitative and qualitative research elements were used: analysis of the modern cost accounting systems was performed; applicability, implications and limitations of the designed model were tested using actual data of the selected industrial company.
\end{abstract}

Keywords: Activity-Based Costing; Time Driven Activity Based Costing; Service-Based Costing; Duration Based Costing; LEAN accounting; Full Cost Calculation.

\section{Introduction}

Success of a business enterprise in the present-day dynamic business context is influenced by professionally managed and controlled factors of competitive advantage: quality, price, cost optimization, technological innovation, etc. In the search for internal reserves for improvement of competitive ability, companies are seeking to identify and eliminate the corporate non-value adding processes. In this case, the use of ideal or rational absorption costing instead of a full costing approach can be preferable (Santana et al., 2019).

Full product cost calculation is topical to majority of the production companies. Dividing costs into direct and indirect is important in order to establish measures of diminishing costs (Batrancea et al., 2019). Accurate indirect cost allocation may significantly influence product profitability, pricing and management decisions: the products to be produced; verification of coverage of the total product costs by the product-selling price, etc.

Activity Based Costing (ABC) is the first of a kind modern management accounting system relying on allocation of indirect costs to products or services based on activities. ABC takes into account the dynamics of indirect costs, allows to determine the cause of these costs, and also gives the possibility to assign (refer) the costs of the process for the finished product (Pawłyszyn, 2017). The ABC involves activity monitoring and profitability analysis performed in parallel (Cooper \& Kaplan, 1988), and enables highly accurate indirect cost allocation (Fisher \& Krumwiede, 2015; Azevedo, 2015). That prompted the need to explore new methods of cost allocation as well as improvement of the $\mathrm{ABC}$. As a result, modified versions were developed: Time Driven Activity Based Costing TDABC (Kaplan \& Anderson, 2004), Monte Carlo ABC (Rauner et al., 2005), Fuzzy ABC (Nachtmann \& Needy, 2001; Esmalifalak et al., 2014), Grey Activity Based Costing G-ABC (Raeesi \& Amini, 2013), Service-Based Costing SBC (Dorn \& Seiringer, 2013), Duration Based Costing DBC (Lelkes \& Deis, 2013; Lelkes, 2015).

Recently, implementation of LEAN production management system has been rapidly growing in popularity among production companies. LEAN philosophy towards production management is contrary to the conventional production management approach, and, in certain aspects, LEAN accounting often contradicts conventional organization of accounting processes (Obara \& Wilburn, 2012; Monroy et al., 2014; Pickering \& Byrnes, 2016; Wnuk-Pell, 2018). LEAN philosophy requires adapting all corporate processes to the customer's needs. Where LEAN accounting is applied, indirect cost allocation requires finding an additional methodology, which would not conflict with the LEAN concept (simplicity, abandoning of excess processes, reduction of bureaucracy, etc.).

The aim identified for the research presented herein: design of the full product cost calculation model adapted to a production company following analysis of the $\mathrm{ABC}$ modifications and LEAN accounting principles as well as their practical integrability and applicability.

The research starts with the analysis of theoretical basis of the ABC modifications (TDABC, S-BC, DBC) and LEAN accounting. The innovative full product cost calculation 
model has been developed using the analysis, comparison and analogy methods, by interpretation of the findings of previous research works. The model employs components of the above-mentioned ABC modifications and LEAN accounting. Applicability, implications and limitations of the model have been verified by practical experiment in the selected industrial company. The research is specific in that it employed the interpretive research methods, where other research participants' (business owners, managers, and ordinary employees) subjective opinion about the phenomena analysed extend researchers' knowledge. This face-to-face interaction among the researchers, practitioners and investors in view of the needs of each group has enabled the authors to select the best methods for formation of the full cost calculation model and verify its quality using financial calculations.

\section{Literature Review}

Under the ABC approach, an enterprise is a complex of activities. This approach involves identification of the activities performed at the company, verification and assessment of their necessity and benefit. Where non-value adding activities have been identified, the focus is placed on their elimination from the chain of activities. At the same time, the most beneficial activities contributing to creation of a product are identified as well. The ABC enables clear identification of the factors (drivers) which influence variation of indirect costs. Al-Halabi \& Shaqqour (2018), Abbas (2014) have been claiming that the ABC might lead to greater competitive ability of businesses.

Despite the benefits of the ABC, great criticism towards this system has been expressed. In efficiency assessment of this system, timely access to information, its accuracy and compliance with the consumer's requirements are important. The economic factor has been exactly the reason of criticism: information collection and submission are not supposed to cost more than the benefit provided by the information obtained. According to Cheung et al. (2013), the process of calculation under the $\mathrm{ABC}$ methodology is considerably time- and labour-intensive, but the cost of products calculated under the ABC differs from the cost calculated using conventional system only by $2.5-6.4 \%$.

Numerous authors have named labour-intensity as the key weakness of the ABC. Top managers should realize the prospective financial benefit of implementation of a new accounting system, and motivate the employees accordingly. According to Berry (2014), an organization should develop clear understanding of the expected financial benefit when choosing a cost accounting system.

In practice, determining the amount of resources used in specific activities and the share of these costs attributable to specific products may be complicated (Raeesi \& Amini, 2013). The larger and more structurally complex a company is, the more processes or products it has, the less likely implementation and functionality assurance of the $\mathrm{ABC}$ are.

From its very beginning, the $\mathrm{ABC}$ has gone through a series of improvements. According to Abbas (2014), the $\mathrm{ABC}$ was upgraded in view of the growing business needs, starting with profitability control, performance of financial and strategic planning, ending with operational process management, human resource management and planning.
Fuzzy ABC is the fuzzy mathematical model integrated into the $\mathrm{ABC}$, mathematically balancing out the effect of fluctuation of non-constant and variable data (Esmalifalak et al., 2014). Rauner et al. (2005) has presented the ABC methodology modified with the Monte Carlo simulation. Monte Carlo simulation technique enables quantitative analysis of non-constant and variable data. Nachtmann \& Needy (2003) have applied the combination of both models - Fuzzy and Monte Carlo - to the ABC. Nonetheless, these $\mathrm{ABC}$ upgrades have not provided any solution to the issue of complex and complicated data collection.

Kaplan \& Anderson (2004) proposed a Time Driven Activity Based Costing (TDABC), replacing the variety of cost driver types with a single - time consumption, reducing the number of activity types. TDABC implies analysis on the unit or process level. TDABC simulates the actual process of corporate operations and does not require as complex data calculation, accumulation and processing as the $\mathrm{ABC}$, its predecessor. The authors have provided rationale behind practical applicability of the TDABC by the example of a large international product distribution company (Kaplan \& Anderson, 2004)

Application of both the ABC and TDABC has been analysed using the examples of service sector: construction project management (Kim \& Ballard, 2001), electronic warehouse (Pawlyszyn, 2017), health care (French et al., 2013; Campanale et al., 2014; Kaplan, 2014; Esmalifalak et al., 2014; Hoozee \& Hansen, 2017; Balakrishnan et al., 2018), library services (Siguenza-Guzman et al., 2014), education (Berry, 2014), postal service (Kujacic et al., 2015). This is because the indirect costs comprise greater share of the service cost. Companies often tend to possess the characteristics of the both - the service and the production. Both sectors possess specific distinctive features: for the service sector, it is difficult to calculate intangible resources, while production encounters difficulties in measurement of work in progress or new product development costs (Terzioglu \& Chan, 2013).

Oker \& Adiguzel (2010) have verified TDABC applicability using the example of a large production company: while the TDABC can be applied to production, this is not as easy as in case of service companies. Key advantage of the TDABC is the ability to identify free production capacities and shortage of capacities in the course of processes (Oker \& Adiguzel, 2010; Monroy et al., 2014). This analysis is performed only by measurement of the work time, while for actual production, measuring several parameters (tones, $\mathrm{m}^{2}$, etc.) would be reasonable. This leads to the conclusion that key advantage of the TDABC may turn into limitation of the system if applied to production. Having analysed the issue of assessment of unused capacities, Tanis and Ozyapici (2012) have proposed primarily categorizing the unused capacities into real, compulsory unused and unusable capacities, thereby increasing efficiency of the TDABC analysis.

Hoozee \& Hansen (2017), who have compared the ABC and TDABC, have determined that, for the both systems, the error of product cost increases in case of greater correlation between resource diversity and number of activities. TDABC offers higher accuracy when resources are more linked to activities, while the ABC is more accurate when activities are more linked to products. The findings by the 
authors who have analysed the TDABC at production companies suggest that successful implementation of the system should be considered prior to choosing this system.

One of $\mathrm{ABC}$ upgrades are the Grey Activity Based Costing (G-ABC) proposed by Raeesi \& Amini (2013) and based on the Grey systems theory (Liu et al., 2012), when data are classified as white (accurate), grey (average accuracy) and black (highly inaccurate). The company determines the coefficients for grey data intervals and introduces the grey data into the end-product cost under the $\mathrm{G}-\mathrm{ABC}$ formulae.

Service-Based Costing (S-BC) methodology has been developed for service companies (Dorn \& Seiringer, 2013). The S-BC model is based on the Customer Integration Factor, which is subject to assessment by four customer's influence parameters: depth, intensity, frequency, duration.

Duration Based Costing (DBC) is the upgraded ABC proposing that product costs are calculated according to the duration of its production cycle (Lelkes \& Deis, 2013). Authors of the DBC model have completely omitted identification of individual activities, but have rather allocated indirect costs to the amalgamated time unit production cycle per product batch. It is claimed that a production cycle covers the duration of several activities performed, and in application of this method to a production company, indirect cost allocation is as accurate as in the case of the ABC and TDABC, but less labour-intensive.

LEAN is a production management system covering production planning, staff training, stock management, regular improvement of all production and administration processes, and elimination of all types of production losses. LEAN accounting is just a component of this comprehensive system. LEAN philosophy is opposite to the conventional approach towards production management, and LEAN accounting is often controversial in certain aspects to conventional accounting. LEAN requires adapting all the corporate processes to customer's needs. Implementation of the LEAN at organizations results in significant changes, starting with the managers' and employees' approach towards organization of production.

LEAN accounting goals are implemented under three key principles: visual management, value stream management, continuous improvement (Monroy et al. 2014). Visual accounting implies presentation of weekly, monthly, quarterly financial results in the form of graphs, images, colour tables, replacing the standard forms of statements. Value stream management implies presentation of financial results by identifying the objects that create the value. For this analysis, Günduz (2015) has proposed using non-financial indicators, such as sales per person, average cost per unit, dock-to-dock day, and first time through.

Pickering \& Byrnes (2016) have proposed a LEAN income statement. The sample LEAN income statement is divided into value stream and business sustaining cost columns. The authors have emphasized the importance of the change of raw materials in this statement. This indicator is important as it may lead to reduction of cash flows and provide information on changes in the stockyard. LEAN requires reducing the level of raw materials to the minimum and purchasing the raw materials exactly in the amounts required for production under respective orders. Aimed at increasing the efficiency of the value stream, LEAN accounting does not pay attention to indirect cost allocation to specific products. According to Günduz (2015), companies tend to calculate the average cost per unit using very different methods. LEAN accounting allows for successful integration of the activity based cost accounting for indirect cost allocation, by minor simplification and reduction of the level of detail as well as adaptation to the specifics of company (Obara \& Wilburn, 2012). The authors have proposed assessing indirect costs, primarily, by rating the need for the activity performed according to the complexity of customer requirements.

The assessment is organized by four criteria: customer support requirements, bill of material necessary for customer's order (product), payment specifics, and requirements to product packaging and shipping. The requirement for indirect costs increases from 4 points (the lowest requirement) to 9 points (the highest requirement). Customer's points are linked to the cost coefficient that is used to allocate the indirect costs. These methodology is similar to the Customer Integration Factor (CIF) under the S-BC model (Dorn \& Seiringer, 2013). CIF is assessed by four customer's influence parameters - depth, intensity, frequency, and duration - for product cost calculation.

Fisher \& Krumwiede (2015) refer to simplification of accounting as the advantage of LEAN. Otherwise, less stringent cost control, when units use common resources, is disadvantage of the system. LEAN accounting simplifies the accounting processes, and resource control would be difficult to achieve without bureaucratic administration, which is conceptually opposite to LEAN philosophy. Fisher \& Krumwiede (2015), Pickering \& Byrnes (2016) emphasize that LEAN accounting does not require allocation of indirect costs to the end-product. Advocates of LEAN have noted that it is the market rather than the production costs that determines the prices. Pickering \& Byrnes (2016) have admitted that the less costs can be attributed to the value stream of a product, the less effective the profitability analysis is. This means that the production companies, which have implemented LEAN accounting, will eventually encounter the issue of correct allocation of indirect costs to the product cost.

When comparing LEAN accounting to the ABC and its modifications, it has been noticed that LEAN is a unique idea of value stream measurement - no other accounting system has attempted to identify and assess value streams in the accounting. Comparison of LEAN with ABC has suggested that they contradict each other in the simplification of the LEAN accounting processes and the $\mathrm{ABC}$ requirement to perform too detailed data collection.

The common aspect of the LEAN and TDABC is that they both measure and analyse unused production capacities. Production duration for a product is one of the value stream measurement indicators under the LEAN and the DBC (Lelkes \& Deis, 2013). It would also be reasonable to integrate customer rating into LEAN accounting (Obara \& Wilburn, 2012), which is similar to the CIF under the SBC (Dorn \& Seiringer 2013).

\section{Full Product Cost Calculation Model}

The analysis of ABC, TDABC, S-BC, DBC and LEAN accounting has suggested that the $\mathrm{ABC}$ generates very 
accurate data on product cost, but the labour-intensive data collection, processing and interpretation are the reasons why this system is difficult to apply to production companies. In the TDABC, different types of cost drivers have been replaced with time consumption, and the number of activity types has been reduced. The DBC is centred on the production duration, while the $\mathrm{S}-\mathrm{BC}$ introduces the factor of customer complexity into cost calculation. LEAN is centred on the results, but does not place focus on the allocation of indirect costs. Hence, customized methodology must be explored for allocation of indirect costs to products. For this purpose, the Full Product Cost Calculation Model for an Industrial Company (Figure 1) has been designed. The model has been designed by integration of elements of other systems into the LEAN accounting: ABC activities conducted in all operational processes at the company; TDABC time driver as a conversion element, S-BC customer rating that replicates the significance of customer's needs, and DBC production duration reflecting the production cycle.

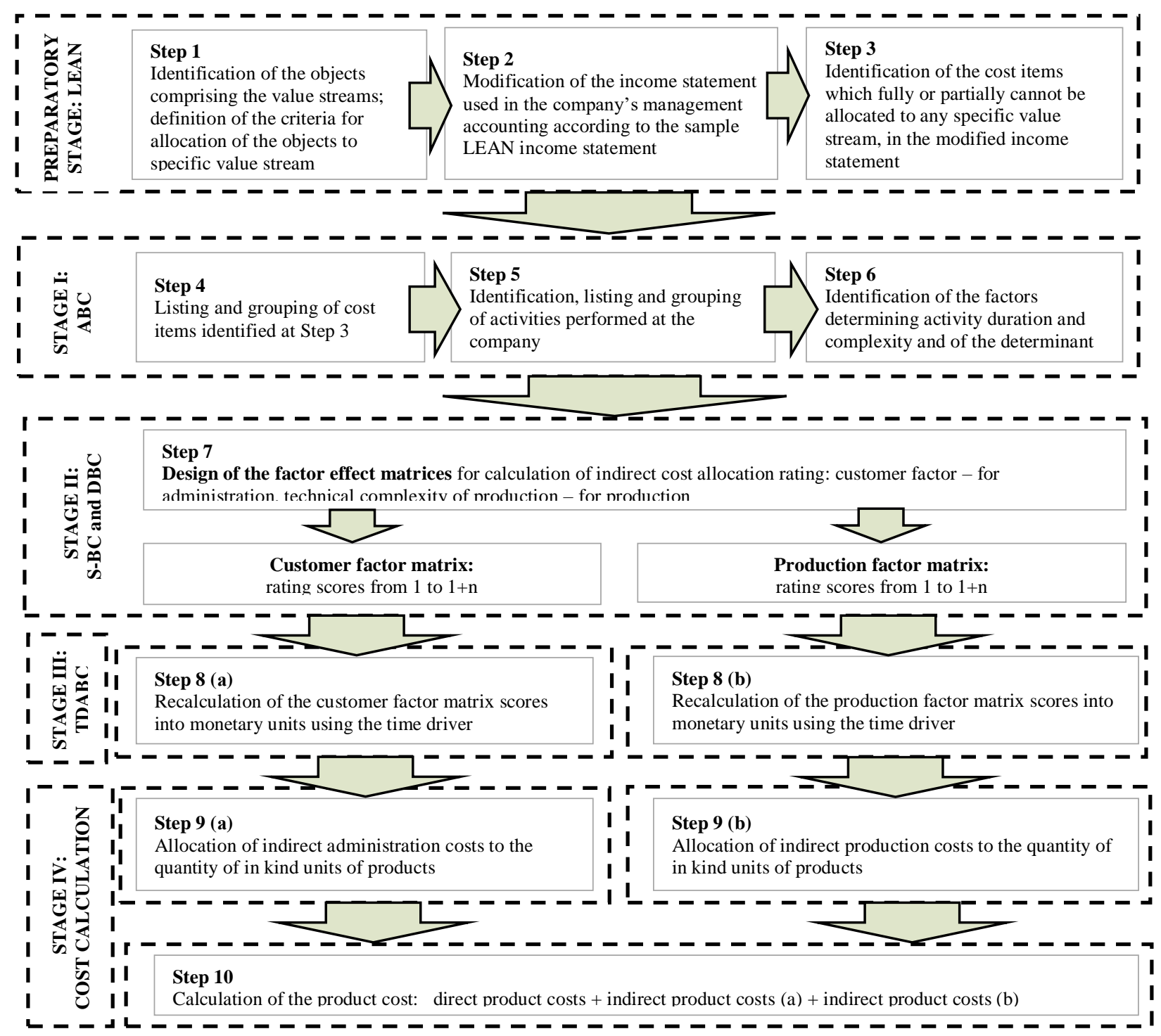

Figure 1. Full Product Cost Calculation Model

The preparatory stage of the model is based on the modified LEAN accounting income statement (step 1-2), divided into value stream objects (Pickering \& Byrnes, 2016). The aim of the modification: to eliminate the weakness of the conventional accounting - the absence of control over the value stream. In view of the proposal by Monroy et al. (2014), the value stream objects and business sustaining value stream have been identified (step 3). LEAN does not specify allocation of indirect costs (Gunduz, 2015; Obara \& Wilburn, 2012). Modification of the statement requires identifying the items of indirect costs, which have not been allocated to any specific value stream. At the same time, the questions raised by Fisher \& Krumwiede (2015) should be answered: which cost items should be included into the product cost? Success of the full product cost calculation model may be measured by regrouping the business sustaining costs into the specific value streams - the less non-allocated business sustaining costs have remained, the more efficient this model is.

Stage $I$ is the stage of identification of the ABC activities. It is intended to eliminate the weakness of a LEAN accounting - non-consideration of the indirect cost allocation. LEAN accounting might integrate the $\mathrm{ABC}$ element for indirect cost allocation (Obara \& Wilburn, 2012). The activities in the model are grouped by the attribute of allocation to production or administration costs (steps 4-5). This grouping extends the ABC and LEAN accounting. Then, 
the factors of duration and complexity and the determinant of the activity are identified (step 6).

Stage II is design of the matrices of product complexity factors. It brings essential improvement into the $\mathrm{ABC}$, as identification of the factors of cost formation accounts for the LEAN concept of customer orientation. The main factor in administration activities may be the specifics of customer's requirements, which is identical to the CIF, proposed in the S-BC (Dorn \& Seiringer, 2013). The determinant in production activities may be the complexity and specifics of the production. The factors of activity duration and complexity should be described in details: if satisfaction of customer's requirements has been found to influence the need for a certain activity, the customer's requirements should be broken up into highly simple to highly complex. The detailed customer's requirements should then be assessed by points from 1 to $1+\mathrm{n}$. Similar matrix is designed for calculation of the rating for determinant of production. It is recommended that the production matrix accounts for one of the key production factors - the lead time. This shifts the managers' focus from the activities to their duration. Hence, it means that the model involves the element of the DBC (Lelkes \& Deis, 2013 ) - the amalgamated time unit - the production cycle.

Stage III involves attribution of the value expression to the factor significance scores. For this, TDABC time driver element is used. TDABC identifies the available shortage of the production capacities (Oker \& Adiguzel, 2010; Monroy et al., 2014; Santana et al., 2017). This correlates to the LEAN idea of continuous improvement. Although one factor is used for significance of the factors, the model strictly follows division of the activities into the production and administration activities.

In attribution of a value to the significance points of factors, the significance points of factors should be listed in the ascending order. Then, the amounts of the indirect costs subject to allocation should be calculated individually for administration and production; work time per period of cost allocation should be calculated, again, individually for staff in administration and indirect staff in production; cost amounts are divided by actual working hours - individually for the employees in administration and indirect employees in production. The resulting values should then be attributed to mean factor significance scores $\mathrm{X}$. For an increasing factor significance score $(\mathrm{X}+\mathrm{N}, \mathrm{X}+2 \mathrm{~N}$, etc.), the hourly pay should be increased respectively $(+\mathrm{N}$ Eur/h$)$, while for a decreasing score (X-N, $\mathrm{X}-2 \mathrm{~N}$, etc.), the hourly pay is to be reduced (-N Eur/h). The higher the amount of money increased and the lower the mean value decreased, the greater is the difference between the lowest and the highest values. This difference is expected to repeat the difference between time costs at a company incurred in providing support to customers, from the simplest to the most difficult.

The result of stage III is the amount of costs per working hour, calculated according to the scores of factors of production and administration costs. The average amount of costs may be subject to variations from period to period, depending on the number of hours of actual work. To balance out the fluctuations, calculating the average amount of costs per working hour for a longer period, e.g., using the data of three-month period, is recommended. It is also important to review the cost composition: whether or not any large one-off cost amounts have been included into the accounts, in which case, the share of the amount of one-off costs in proportion to the respective period should be used for the calculation. It is possible that one-off costs incurred will not be included into calculation of product cost at all.

Stage IV is full product cost calculation following allocation of indirect costs to the products. The data needed at this stage: total quantity of the products produced during the period, by customers, or by type of products; actual hours of work calculated at the previous stage. The last stage is completed by step 10, where the calculated sales and administration costs and calculated indirect production costs are added to the direct product costs:

$$
\begin{aligned}
& \sum \mathrm{FC}=\mathrm{DC}+\mathrm{IC}(\mathrm{p})+\mathrm{IC}(\mathrm{a}) \\
& \text { where FC - full product cost } \\
& \text { DC - Direct Costs, } \\
& \mathrm{IC}(\mathrm{p}) \text { - indirect production costs, } \\
& \mathrm{IC}(\mathrm{a}) \text { - indirect administration costs. }
\end{aligned}
$$

The main requirement set for the designed full product cost calculation model is varying allocation of a share of indirect costs in view of the technological complexity of products and customer's requirements. In view of the results generated by the interviews with business owners and company managers, success of the model shall be assessed by decrease of business sustaining costs: completely successful - decrease by $>90 \%$, proven - decrease by 70-90 \%; not proven - decrease by $<70 \%$.

\section{Application of the Model}

The full product cost calculation model has been verified using analytical data of production company GI. The company operates in production of customized piece-works, the volumes of which are expressed in $\mathrm{m}^{2}$. Each product is one-of-a-kind, and the company applies the Job order costing method without calculating the full product cost. Company GI directly includes main raw materials, costs of reject production, payroll in production, transportation costs into the product cost, while electricity, depreciation, repair of manufacturing plant, and auxiliary production costs are accounted for indirectly. Product weight is the allocation basis of indirect costs. The model would enable accurate allocation of indirect costs to the products produced. An important limitation is that the company applies an orderspecific cost calculation method, which needs to be considered when designing the indirect cost allocation model for the company.

As intended by the preparatory stage of the model (Figure 1), the Statement of Operating Results of management accounting at production company GI has been modified (Table 1) according to the vertical breakup into the value creating objects (Pickering \& Byrnes, 2016). The products are coded by the respective code names as the value stream objects: MONO, LAM, and IGU. As proposed by Pickering \& Byrnes (2016), Günduz (2015) the following items have been added to the conventional income (loss) statement of company GI:

- Full costs Eur $/ \mathrm{m}^{2}$ - covers direct and indirect costs per product $\mathrm{m}^{2}$; this item has provided a clear information indicating certain pricing related solutions;

- Inventory adjustment Eur - item for raw materials in the statement of financial position at the end of period is compared to the inventory balance at the start of period; 
Neringa Stonciuviene, Ruta Usaite-Duonieliene, Danute Zinkeviciene. Integration of Activity-Based Costing Modifications...

negative change immediately indicates issues in inventory management to the managers;

- Gross profit before inventory Eur - the indicator is calculated prior to the presentation of information on inventory adjustment; the indicator demonstrates how the costs are covered not taking into account for the inventory investments;

- Value stream profit Eur; in contrast to calculation of total profit, this item accounts for the effect of the inventory adjustment; LEAN system follows the idea that greater raw material costs have had negative effect on the actual profit, and, in case of decreasing level of raw materials, additional cash flow is 'released', which creates the assumption for generation of greater profit;

- Return on sale \% is the indicator calculated as the total and for each value stream individually; the indicator shows the difference in return on sale generated by each type of products, and indicates whether the return on sale is sufficient enough to cover the total costs incurred for creation of the product.

Table 1

Modification of the Statement of Operating Results of Company GI According to the LEAN Value Stream Principle

\begin{tabular}{|c|c|c|c|c|c|}
\hline Indicators & Total & $\begin{array}{c}\text { Value stream } \\
\text { MONO }\end{array}$ & $\begin{array}{c}\text { Value stream } \\
\text { LAM }\end{array}$ & $\begin{array}{c}\text { Value stream } \\
\text { IGU }\end{array}$ & $\begin{array}{c}\text { Business } \\
\text { sustaining }\end{array}$ \\
\hline Total volume $\mathrm{m}^{2}$ & 133423 & 29353 & 12008 & 92062 & $\mathrm{x}$ \\
\hline Average price per $\mathrm{m}^{2}$ & 123.11 & 46.89 & 120.50 & 147.75 & $\mathrm{x}$ \\
\hline Full costs per $\mathrm{m}^{2}$ & 110.98 & 60,59 & 126.81 & 120.59 & $\mathrm{x}$ \\
\hline Sales revenue & 16468829 & 1386429 & 1449981 & 13632419 & - \\
\hline Quality claims (-) & $(43048)$ & $(10062)$ & $(3007)$ & $(29979)$ & - \\
\hline Cost of goods sold & 13183381 & 1277457 & 1238552 & 7519378 & 3147994 \\
\hline Direct materials & 7013925 & 1022106 & 580421 & 5411395 & - \\
\hline Salary & 2606692 & 107396 & 348137 & 605815 & 1545344 \\
\hline Depreciation, repair and maintenance & 1884006 & 27751 & 184281 & 319538 & 1352436 \\
\hline Other costs & 1678757 & 120203 & 125714 & 1182625 & 250215 \\
\hline Indirect costs & $\mathrm{x}$ & 219635 & 148998 & 2597592 & $(2966225)$ \\
\hline Gross profit before inventory & 3242400 & $(120725)$ & 59424 & 3485470 & $(2966225)$ \\
\hline Inventory adjustment & $(136842)$ & - & $(13795)$ & $(98123)$ & $(24924)$ \\
\hline Value stream profit & 3105558 & $(120725)$ & 45629 & 3387347 & $(206693)$ \\
\hline Sales and administration costs & 1760308 & 281503 & 149039 & 1082851 & 1593306 \\
\hline Operating profit (loss) & 1345250 & $(402228)$ & $(103410)$ & 2137494 & $(286606)$ \\
\hline Return on sales \% & 8.2 & -29.0 & -7.1 & 15.7 & -1.7 \\
\hline
\end{tabular}

Costs were allocated to MONO, LAM, and IGU value streams. Modified Statement demonstrated that the company had not allocated $\sim 90 \%$ of sales and administration costs and $\sim 23 \%$ of the indirect costs in the costs of goods sold. These costs were therefore the object for application of the full product cost calculation model. As part of fulfilment of the requirements under stage II, activities performed of company GI were grouped under the horizontal breakdown principle of the Statement. All activities performed in production were attributed to the cost group, while the sales and administration activities were attributed to the administration group (Table 2).

Table 2

Grouping of Activities at Company GI and Attribution of the Cost Determinants

\begin{tabular}{|c|c|c|c|c|}
\hline \multirow{2}{*}{$\begin{array}{l}\text { Cost items in the } \\
\text { Statement of Operating } \\
\text { Results }\end{array}$} & \multirow[b]{2}{*}{ Activity description } & \multicolumn{3}{|c|}{$\begin{array}{l}\text { Ratios of the determinants of complexity } \\
\text { and duration of performance of the activity }\end{array}$} \\
\hline & & $\begin{array}{c}\text { Specifics of } \\
\text { customers' } \\
\text { requirements }\end{array}$ & $\begin{array}{l}\text { Specifics of the } \\
\text { production } \\
\text { technology }\end{array}$ & Other \\
\hline \multicolumn{5}{|c|}{ Production Costs } \\
\hline \multirow{9}{*}{$\begin{array}{l}\text { Payroll in production; } \\
\text { Equipment depreciation; } \\
\text { Equipment repair and } \\
\text { maintenance; } \\
\text { Other production costs }\end{array}$} & Organization of the production work, provision with equipment, etc. & 0.1 & 0.9 & - \\
\hline & $\begin{array}{l}\text { Calculations of the received orders, processing of drawings and } \\
\text { submission of the production tasks to the production unit, supervision } \\
\text { of performance in the production process }\end{array}$ & 0.85 & 0.15 & - \\
\hline & Adjustment, repair of equipment & - & 1 & - \\
\hline & Ordering of raw materials, warehouse management & 0.6 & 0.1 & 0.3 \\
\hline & Production planning and optimization, process related consultations & 0.2 & 0.7 & 0.1 \\
\hline & Electricity, water, heating system maintenance & - & 0.9 & 0.1 \\
\hline & Quality inspection in production processes & - & 1 & - \\
\hline & Investigation of customer claims & 1 & - & - \\
\hline & Cleaning, sorting, packaging of the products, logistics, etc. & 1 & - & - \\
\hline & Sum of coefficients in production: & 3.75 & 4.75 & 0.5 \\
\hline \multicolumn{5}{|c|}{ Administration Costs } \\
\hline \multirow{5}{*}{$\begin{array}{l}\text { Payroll in administration; } \\
\text { other administration costs }\end{array}$} & Selection, training of staff, occupational safety & 0.2 & 0.5 & 0.3 \\
\hline & $\begin{array}{l}\text { Organisation, support, maintenance of office and office environment } \\
\text { administration }\end{array}$ & 0.3 & - & 0.7 \\
\hline & $\begin{array}{l}\text { Organisation of work of the office staff, provision with the facilities } \\
\text { for work }\end{array}$ & 0.2 & 0.1 & 0.7 \\
\hline & Accounting and financial management & 0.6 & 0.2 & 0.2 \\
\hline & Maintenance of the IT systems & - & 0.9 & 0.1 \\
\hline $\begin{array}{l}\text { Sales personnel payroll; } \\
\text { business trips; etc. }\end{array}$ & $\begin{array}{l}\text { Search for new customers; provision of quotes; } \\
\text { communication with existing customers, after-sales support }\end{array}$ & 1 & - & - \\
\hline & Sum of coefficients in administration: & 2.1 & 1.7 & 1.2 \\
\hline
\end{tabular}


To assess the determinants of complexity and duration of performance of the activities, and identify their weight ratio, the interview method was applied, and heads of the corporate units were interviewed additionally. The results of the survey showed that the activities have very different meanings, which were reflected by coefficients.

Two key determinants of performance of an activity have been identified in the interviews of focus groups, comprised of the supply and sales managers and heads of production units: specifics of customer's requirements and specifics of production technologies. Coefficients of each activity range from 0 to 1 . E.g., organization of the production work has little relevance when the focus is from perspective of customer requirements $(0.1)$, and the specifics of the production technology (0.9). The factor of customer's requirements is essentially close to the CIF under the S-BC (Dorn \& Seiringer, 2013). Specifics of suppliers, market fluctuations, fiscal or legal environment, unforeseen externalities have been attributed to other factors. Costs in production are influenced by specifics of production technologies (sum of coefficients 4.75), in administration - by specifics of customer's requirements (sum of coefficients 2.1).

In view of significance of the determinants of costs, the complexity rating - from extremely simple to extremely complex - for each of the determinants mentioned will be calculated under the matrix principle during stage II of the model. Complexity is rated by scores from $n$ to $n+1$.
Customer's requirements are assessed in view of the findings identified during the focus groups interviews: delivery conditions, packaging specifics, quality requirements, contractual specifics and history of payments, specifics of support, product composition and its modifications during implementation of the order. Contractual conditions related to customer's payments and history of payments are also subject to assessment by rating points of customer's requirements, as customer's preferences regarding exclusive payment conditions (letter of credit, long credit period, delayed payments, etc.) create additional costs to financial activity and administration costs to the company. In view of the above specifics, the matrix of customer's requirements has been prepared at company GI (Table 3). Considering the complexity of customers' requirements, costs have been rated by scores from 4 to 11 , and specifics of customer's requirements has been broken down into eight levels. E.g., easy customer $(+1)$, with easy ship and pack requirements $(+1)$, EXW, wooden packaging $(+0)$, minimal or standard customer support requirements $(+1)$, short bill of material $(+1)$ was rated at the lowest level, 4 points $(1+1+0+1+1)$.

According to the managers at the production units, the determinant of indirect costs in production activities is the specifics of production technologies. Element of the DBC model proposed by Lelkes \& Deis (2013) - the amalgamated time unit - production cycle - has been used in development of the production rating matrix.

Table 3

Matrix of the Requirements by Company GI Customers for Indirect Cost Rating

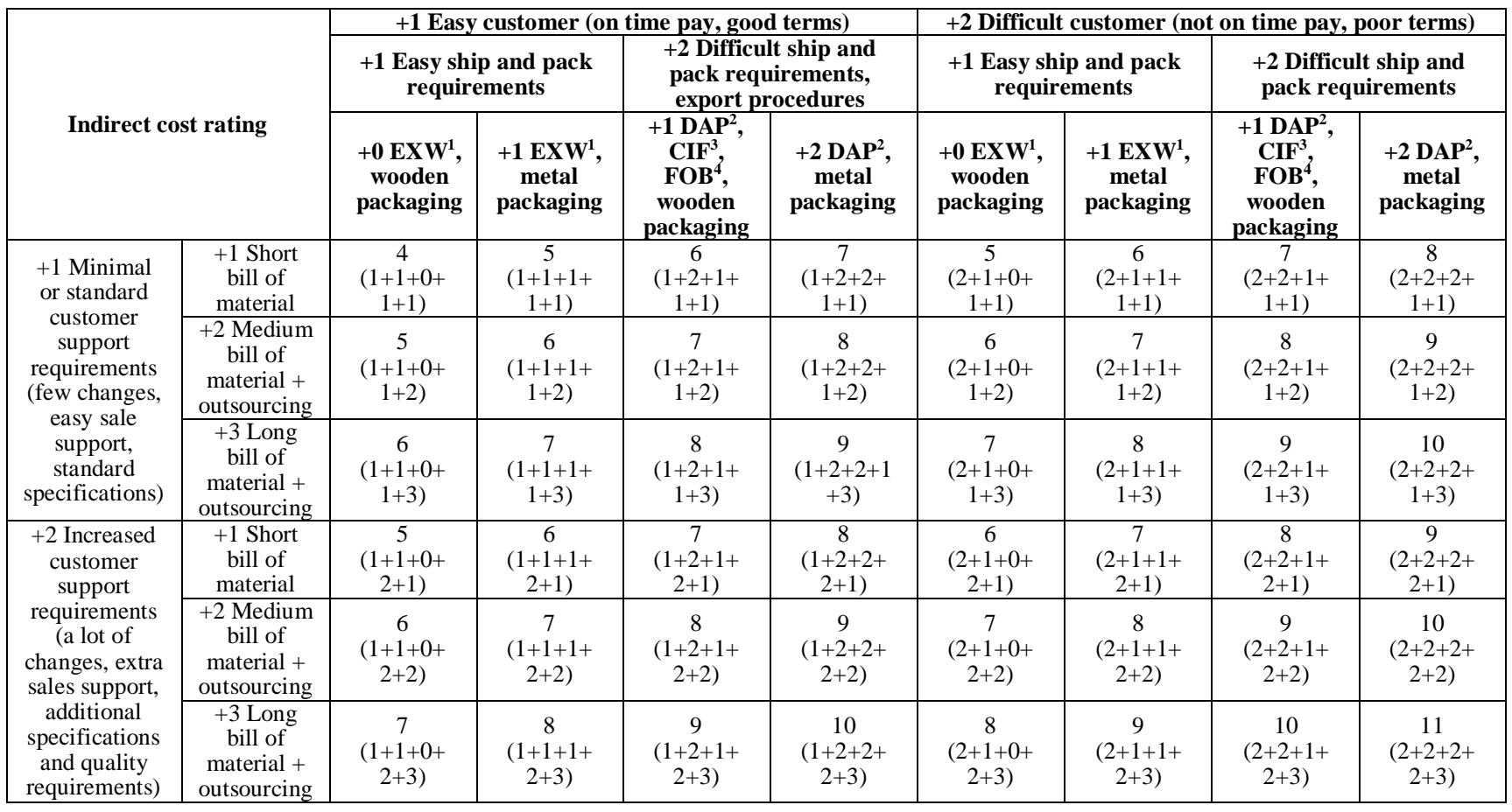

${ }^{1}$ EXW (Ex Works) is an international trade term by which a seller makes the product available at a designated location, and the buyer incurs transport costs;

${ }^{2} \mathrm{DAP}$ (Delivered at place) is an international trade term used to describe a deal in which a seller agrees to pay all costs and suffer any potential losses of moving goods sold to a specific location; ${ }^{3} \mathrm{CIF}$ (Cost, Insurance and Freight) means the seller pays costs, freight and insurance ag ainst the buyer's risk of loss or damage in transit to destination;

${ }^{4} \mathrm{FOB}$ (Free On Board) is a trade term requiring the seller to deliver goods on board a vessel designated by the buyer

A production cycle covers the duration of several activities performed, and application of this method to an industrial company results in fairly accurate and less labourintensive allocation of indirect costs. Performing the assessment by actual output rather than maximum possible output is recommended. To allocate indirect costs under the DBC method, the information on the amount of indirect costs, duration of production cycle, and number of articles 
per batch is required. Consultations by the heads of production units have enabled the authors to calculate the rating of technological complexity factor: from 2 to 6 . The assigned complexity scores have enabled classification of the products into five levels of technological complexity.

Stage III (TDABC) requires attributing the costs to the factor significance rating scores, by using the time driver element. Customers' requirement and technological complexity factors significance scores are ranked from the lowest to the highest. Amounts of the indirect administration and production costs are calculated. The amounts are then divided by the hours worked for administration staff and indirect production staff individually.

It has been determined that, at company GI, the administration and sales staff actually work approximately 41.6 thousand hours annually. Average administration hour fee $(\sim 38 \mathrm{EUR} / \mathrm{h})$, has been calculated according to the information provided in the LEAN value stream statement. This value is attributed to the medium customer factor rating score $X=7$. With the increase of the matrix score $X+1$, hourly fee is increased by 3 EUR, and with the decrease $\mathrm{X}$ 1 , hourly fee is reduced by -3 EUR. Verification of the variation of the final calculated value of the indirect costs per $\mathrm{m}^{2}$ of the product, with the hourly fee increased and decreased by 1, 2, 3 EUR, was performed by trial and error method. The purpose of recalculation of the values was replication of the differing demands in time when working with a difficult and extremely easy customer. According to

Table 4

Calculation of the Indirect Administration Costs Per Product unit at Company GI

\begin{tabular}{|c|c|c|c|c|c|c|c|c|}
\hline \multirow{2}{*}{ Indicators } & \multicolumn{8}{|c|}{ Customer's rating scores } \\
\hline & 4 & 5 & 6 & 7 & 8 & 9 & 10 & 11 \\
\hline \multicolumn{9}{|c|}{ (1) Administration work hours, total h 41600} \\
\hline \multicolumn{9}{|c|}{ 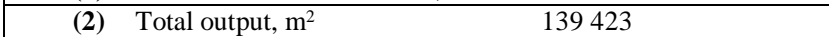 } \\
\hline \multicolumn{9}{|l|}{ (3) } \\
\hline $\begin{array}{l}\text { (4) Fee per hour } \\
\text { worked according } \\
\text { to the customer's } \\
\text { rating EUR/h }\end{array}$ & 29.00 & 32.00 & 35.00 & 38.00 & 41.00 & 44.00 & 47.00 & 50.00 \\
\hline $\begin{array}{l}\text { (5) Administration } \\
\text { costs per } \mathrm{m}^{2} \text { of a } \\
\text { product EUR/ } \mathrm{m}^{2} \\
(5)=(3)^{*}(4)\end{array}$ & 8.65 & 9.55 & 10.44 & 11.34 & 12.23 & 13.13 & 14.02 & 14.92 \\
\hline
\end{tabular}

Full product cost is calculated by adding average indirect production and administration costs to the direct product costs (Table 6). The reason behind decision to add average indirect costs is the objective to see how the product cost varies under the influence of the indirect costs and to avoid high variation of the product costs.

The calculated amounts of indirect costs by types and quantities of products are transferred to the Statement of Operating Results, modified according to the LEAN, for efficiency assessment of the model. The full product cost calculation model is efficient: the unallocated business sustaining cost amounts have decreased by $>90 \%$. The remaining unallocated amount is attributable to the output produced but not sold, with the left-over stock comprising 6 thousands $\mathrm{m}^{2}$. According to the average production (7 points) and administration (4 points) factor rating points, some indirect administration costs $\left(11.34 \mathrm{EUR} / \mathrm{m}^{2}\right)$ and the sales managers at company GI, difference between time consumed per customer with the easiest support requirements and time consumed per customer with extremely difficult requirements may be 1.5- to 2-fold. Recalculation of the customer factor rating into currency, with the selected variable value +/-3 EUR has demonstrated that the difference between the resulting highest and lowest values is 1.7 -fold. The resulting recalculation effect corresponds to the company's assumptions.

Staff in organisation of production work approximately 66.6 thousands hours annually. Average hourly fee in organization of production ( 47 EUR) has also been calculated according to the information of LEAN value flow statement. Each additional production cycle determines considerable increase of costs (by $\mathrm{x}$ times). The average amount has been attributed as the value to the middle score of the matrix $X=4$. With the matrix score increasing $X+1$, the hourly fee increases two-fold, $X+2$ - three-fold, while with the matrix score decreasing $X-1$, the hourly fee is decreased by half, $\mathrm{X}-2$ - decreased by three times.

Stage IV is calculation of the full product cost. Data used at this stage are: total quantity of products produced during the period $\left(\mathrm{m}^{2}\right)$, hours worked, customer's rating and technological rating score of production. Calculation of the indirect administration costs $\left(8.65-14.92 \mathrm{EUR} / \mathrm{m}^{2)}\right.$ is presented in Table 4. Calculation of indirect production costs $\left(7.48-67.31 \mathrm{EUR} / \mathrm{m}^{2}\right)$ is presented in Table 5.

Table 5

\section{Calculation of Indirect Production costs Per Product unit at} Company GI

\begin{tabular}{|c|c|c|c|c|c|}
\hline \multirow{2}{*}{ Indicators } & \multicolumn{5}{|c|}{ Product's rating scores } \\
\hline & 2 & 3 & 4 & 5 & 6 \\
\hline \multicolumn{6}{|c|}{ Hours worked by indirect production staff, total $\mathrm{h}$} \\
\hline \multicolumn{5}{|c|}{ Total output, $\mathrm{m}^{2}$} & 139423 \\
\hline \multicolumn{6}{|c|}{ Indirect production workers time per specific unit $\mathrm{h} / \mathrm{m}^{2}$} \\
\hline$(3)=(1) /(2)$ & & & & & 0.4774 \\
\hline $\begin{array}{l}\text { (4) Fee per hour worked } \\
\text { according to the } \\
\text { production's rating } \\
\text { EUR/h }\end{array}$ & 15.67 & 23.50 & 47.00 & 94.00 & 141.00 \\
\hline $\begin{array}{l}\text { (5) Indirect production } \\
\text { costs per } \mathrm{m}^{2} \text { of a } \\
\text { product EUR/ } \mathrm{m}^{2} \\
(5)=(3)^{*}(4)\end{array}$ & 7.48 & 11.22 & 22.44 & 44.88 & 67.31 \\
\hline
\end{tabular}

some indirect production costs $\left(22.4 \mathrm{EUR} / \mathrm{m}^{2}\right)$ are attributable to single $\mathrm{m}^{2}$ of a product produced, but not sold. Therefore, there are costs (202 000 EUR), which should be allocated to the output produced but not sold. This amount would lead to improvement of the operation result.

\section{Conclusions}

The presented research dedicated to the full cost calculation integrates the interpretive research as well as analysis of actual data. In formation of the full cost calculation model for products, analysis of the modern cost accounting systems was performed, and the advantages of each of the system were included into the model designed. 
Calculation of Full Product cost at Company GI

\begin{tabular}{|c|c|c|c|c|c|c|c|}
\hline Product & $\begin{array}{c}\text { Actual quantity } \\
\text { sold in specific } \\
\text { units } \mathbf{m}^{2} \\
\end{array}$ & $\begin{array}{c}\text { Average direct } \\
\text { costs per specific } \\
\text { unit } \mathbf{~ m}^{2} \\
\end{array}$ & $\begin{array}{c}\text { Customer } \\
\text { rating } \\
\text { score } \\
\end{array}$ & $\begin{array}{l}\text { Administration costs } \\
\text { per specific unit } \mathbf{m}^{2}\end{array}$ & $\begin{array}{l}\text { Production } \\
\text { rating score }\end{array}$ & \begin{tabular}{|c|}
$\begin{array}{c}\text { Indirect } \\
\text { production costs per } \\
\text { specific unit } \mathbf{~ m}^{2}\end{array}$ \\
\end{tabular} & $\begin{array}{c}\text { Full cost per } \\
\text { specific unit } \\
\text { EUR } / \mathbf{m}^{2} \\
\end{array}$ \\
\hline \multirow{2}{*}{ MONO } & 21677.88 & \multirow{2}{*}{43.52} & 4 & 8.65 & 2 & 7.48 & 59.65 \\
\hline & 7685.12 & & 8 & 12.23 & 2 & 7.48 & 63.23 \\
\hline \multirow{5}{*}{ LAM } & 200.17 & \multirow{5}{*}{103.14} & 7 & 11.34 & 4 & 22.44 & 137.81 \\
\hline & 2282.51 & & 8 & 12.23 & 3 & 11.22 & 126.59 \\
\hline & 7662.07 & & 9 & 13.13 & 3 & 11.22 & 127.49 \\
\hline & 1312.55 & & 9 & 13.13 & 4 & 22.44 & 138.71 \\
\hline & 77.42 & & 9 & 13.13 & 5 & 44.88 & 161.15 \\
\hline \multirow{14}{*}{ IGU } & 32.45 & \multirow{14}{*}{83.49} & 4 & 8.65 & 4 & 22.44 & 114.58 \\
\hline & 805.16 & & 5 & 9.55 & 4 & 22.44 & 115.48 \\
\hline & 351.88 & & 6 & 10.44 & 4 & 22.44 & 116.37 \\
\hline & 279.86 & & 6 & 10.44 & 5 & 44.88 & 138.81 \\
\hline & 4391.32 & & 7 & 11.34 & 4 & 22.44 & 117.27 \\
\hline & 41178.01 & & 7 & 11.34 & 5 & 44.88 & 139.71 \\
\hline & 22062.41 & & 8 & 12.23 & 4 & 22.44 & 118.16 \\
\hline & 16367.88 & & 8 & 12.23 & 5 & 44.88 & 140.60 \\
\hline & 1185.34 & & 9 & 13.13 & 4 & 22.44 & 119.06 \\
\hline & 2310.29 & & 9 & 13.13 & 5 & 44.88 & 141.50 \\
\hline & 1191.34 & & 9 & 13.13 & 6 & 67.31 & 163.93 \\
\hline & 558.98 & & 10 & 14.02 & 5 & 44.88 & 142.39 \\
\hline & 682.05 & & 11 & 14.92 & 5 & 44.88 & 143.29 \\
\hline & 593.10 & & 11 & 14.92 & 6 & 67.31 & 165.72 \\
\hline
\end{tabular}

The research is based on the $\mathrm{ABC}$ - allocation of indirect costs, covering multiple activities and cost drivers as well as different cost allocation bases, generating the product cost with high precision. Nonetheless, the methodology is labour-intensive in terms of data collection, processing, and interpretation. It is virtually impossible and too expensive to implement in multi-assortment or complex organizations. During the research, the weakness of the ABC was identified: application of the system does not involve classification of activities into production and administration activities, although administration activities are usually found to include the largest number of non-value creating activities.

The analysis of $\mathrm{ABC}$ modifications has shown three main directions of improvement:

- attempts to apply the mathematical models for accounting and allocation of "grey" data (Fuzzy ABC, Monte Carlo ABC, G-ABC);

- attempts to simplify and speed up the data collection and interpretation processes (TDABC, G-ABC, DBC);

- attempts to improve the methodology by its application to specific areas of operation (DBC, SBC).

TDABC is the simplified ABC - different types of cost drivers have been replaced in the TDABC with a single equivalent type - time consumption, and the number of types of activities has been reduced. Advantage of the TDABC is the analysis of (non-)use of the production capacities. This analysis, however, includes only assessment of the working time. It would be reasonable to assess the capacities by several parameters $\left(\mathrm{t}, \mathrm{m}^{2}\right.$, etc.) in actual production. Hence, that the main advantage of the TDABC in production may turn into the limitation of this system. The latest modifications of the ABC (SBC and DBC) are appealing in terms of their extensions, the elements of which could be used in development of the indirect cost allocation methodology for specific company.
LEAN accounting is centered on measurement of the value stream results, but does not put focus on allocation of indirect costs. This requires finding a methodology, which would not contradict the LEAN concept (simplicity, elimination of excessive processes, etc.), and which would be adapted to the needs of specific company. The idea of simplified and less detailed $\mathrm{ABC}$ could be integrated into LEAN accounting for indirect cost allocation.

The elimination of weaknesses and application of advantages of the $\mathrm{ABC}$ and its modifications has enabled us to design a full cost calculation model. The designed model integrates the following elements: LEAN value streams, ABC activities, TDABC time driver, S-BC customer rating, DBC production duration. According to the data generated by the survey of production managers, the value stream objects were selected, factors determining the complexity and duration of the activities were assessed, and their weight ratios were selected. Proposals by the sales managers were used in formation of the customers' requirements scores.

The developed of the full cost calculation model combines the principles of management accounting systems with different approaches to indirect costs into one model. $\mathrm{ABC}$ methodically justifies the allocation of indirect costs for each produced product, but does not allocate them according to its relationship with production, sales, and administrative processes. LEAN does not focus on allocating indirect costs, but requires adapting all corporate processes to the customer's needs. S-BC responds to this LEAN principle. Accordingly, in the proposed model, the users' needs is one of the key elements of the allocation of indirect costs. It brings essential improvement into the $\mathrm{ABC}$, as identification of the factors of cost formation accounts for the LEAN concept of customer orientation. On the other hand, the closer analysis of the survey data with the focus on the process of determining the significance of activities, allowed to identify the risk of violating the principle of objectivity. TD ABC and DBC focus from the activities to 
Neringa Stonciuviene, Ruta Usaite-Duonieliene, Danute Zinkeviciene. Integration of Activity-Based Costing Modifications...

the duration of activities. The use of the time factor to improve the indirect cost allocation base is recognized by researchers and used in the proposed model. When discussing the model authors' complex approach to the allocation of indirect costs, it should be emphasized that in addition to the aforementioned customer factor, the complexity of the technology is also taken into account. The presented model improved the Statement of Operating Results by providing its preparation and calculation of the key performance indicators according to the value streams.

Verification of the model using the manufacturing company data, reallocation of indirect costs according to new methodology and preparation of modified Statement of
Operating Results revealed economic efficiency of the model- the unallocated business sustaining cost amounts have decreased by $>90 \%$ and the remaining unallocated amount was largely attributable to the output produced but not sold. Assuming that a share of indirect production costs is allocated to the output produced but not sold, the value of output should be increased.

One of the key research limitations was that the model was applied at the company manufacturing customized products suggesting the area for further potential studies: formation of a similar model for mass manufacture of standardized product.

\section{References}

Abbas, K. M. (2014). Some important factors affecting evolution of Activity Based Costing (ABC) system in Egyptian manufacturing firms. Scientific Papers Series Management, Economic Engineering in Agricultural and Rural Development, 14(1), 187-191.

Al-Halabi N. B., \& Shaqqour, O. F. (2018). The effect of Activity-Based Costing (ABC) on managing the efficiency of performance in Jordanian manufacturing corporations-an analytical study. Accounting and Finance Research, 7(1), 262-271. https://doi.org/10.5430/afr.v7n1p262

Azevedo, A. (2015). Innovative costing system framework in industrial product-service system environment. Procedia Manufacturing, 4, 224-230. https://doi.org/10.1016/j.promfg.2015.11.035

Balakrishnan, R., Koehler, D. M., \& Shah, A. S. (2018). TDABC: Lessons from an Application in Healthcare. Accounting Horizons, 32(4), 31-47. https://doi.org/10.2308/acch-52242

Batrancea, I., Batrancea, L., Nichita, A., Gaban, L., Masca, E., Morar, I. D., Fatacean, G., \& Moscviciov, A. (2019). An econometric approach on production, costs and profit in Romanian coal mining enterprises. Economic ResearchEkonomska Istrazivanja, 32(1), 1019-1036. https://doi.org/10.1080/1331677X.2019.1595080

Berry, P. J. (2014). Starting with ABC and finishing with XYZ: what financial reporting model best fits a faculty and why? Journal of Higher Education Policy and Management, 36(3), 305-314. https://doi.org/10.16930/22377662/rccc.v14n42p9-24

Campanale, C., Cinquini, L., \& Tenucci, A. (2014). Time-Driven Activity-Based Costing to improve transparency and decision making in healthcare: A case study. Qualitative Research in Accounting \& Management, 11(2), $165-186$. https://doi.org/10.1108/QRAM-04-2014-0036

Cheung W., Tan, S., Tan, K., \& Sutton, C. (2013). Strategies for implementing Activity-Based Costing in the UK manufacturing industry. 11th International conference on manufacturing research (ICMR2013), 201-206.

Cooper, R., \& Kaplan, R. S. (1988). Measure costs right: make the right decisions. Harvard business review, 66(5), 96103.

Dorn, J., \& Seiringer, W. (2013). A prototype for Service-Based Costing. 46th Hawaii international conference System Sciences (HICSS), 1300-1309. https://doi.org/10.1109/HICSS.2013.56

Esmalifalak, H., Albin, M. S., \& Behzadpoor, M. (2014). A comparative study on the Activity Based Costing systems: traditional, Fuzzy and Monte Carlo approaches. Health Policy and Technology, 4(1), 58-67. http://dx.doi.org/10. 1016/j.hlpt.2014.10.010

French, K. E., Albright, H. W., Frenzel, J. C., Incalcaterra, J. R., Rubio, A. C., Jones, J. F., \& Feeley, T. W. (2013). Measuring the value of process improvement initiatives in a preoperative assessment center using Time-Driven Activity-Based Costing. Healthcare, 1(3), 136-142. https://doi.org/10.1016/j.hjdsi.2013.07.007

Fisher, J. G., \& Krumwiede, K. (2015). Product costing systems: finding the right approach. Journal of Corporate Accounting \& Finance, 26(4), 13-21. https://doi.org/10.1002/jcaf.22045

Gunduz, M. (2015). Value stream performance measurement in LEAN manufacturing business. International Business and Management, 10(3), 40-47. https://doi.org/10.3968/7128

Hoozee, S., \& Hansen, S. C. (2017). A comparison of Activity-Based costing and Time-Driven Activity-Based costing. Journal of Management Accounting Research, 30(1), 143-167. https://doi.org/10.2308/jmar-51686

Kaplan, R. S., \& Anderson, S. R. (2004). Time-Driven Activity-Based Costing. Harvard Business Review, 82 (11), 131138.

Kaplan, R. S. (2014). Improving value with TDABC. Healthcare Financial Management, 68(6), $76-84$. 
Kim, Y. W., \& Ballard, G. (2001). Activity - Based Costing and its application to LEAN construction. Proceedings of the 9th Annual Conference of the International Group for Lean Construction, 6-8.

Kujacic, M., Blagojevic, M., Sarac, D., \& Vesovic, V. (2015). The modified activity-based costing method in universal postal service area: Case study of the Montenegro post. Inzinerine Ekonomika-Engineering Economics, 26(2), 142151. http://dx.doi.org/10.5755/j01.ee.26.2.2818

Lelkes, A. M. T., \& Deis, D. R. (2013). Using the production cycle time to reduce the complexity of Activity-Based Costing systems. Journal of Theoretical Accounting Research, 9(1), 57-84.

Lelkes, A. M. T. (2015). Modifying Duration-Based Costing to Illustrate the Effect of Fixed Costs. Journal of Cost Analysis and Parametrics, 8(3), 165-185. https://doi.org/10.1080/1941658X.2015.1096221

Liu, S., Forrest, J., \& Yang, Y. (2012). A brief introduction to grey systems theory. Grey Systems: Theory and Application, 2(2), 89-104. https://doi.org/10.1108/20439371211260081

Monroy, C. R., Nasiri A., \& Pelaez M. A. (2014). Activity Based Costing, Time-Driven Activity Based Costing and LEAN accounting: differences among three accounting systems' approach to manufacturing. Annals of Industrial Engineering, 11-17. https://doi.org/10.1007/978-1-4471-5349-8_2

Nachtmann, H., \& Needy, K. L. (2001). Fuzzy Activity Based Costing: a methodology for handling uncertainty in Activity Based Costing systems. The Engineering Economist, 46(4), 245-273. https://doi.org/10.1080/00137910108967577

Nachtmann, H., \& Needy, K. L. (2003). Methods for handling uncertainty in Activity Based Costing systems. The Engineering Economist, 48(3), 259-282. https://doi.org/10.1080/00137910308965065

Obara, S., \& Wilburn, D. (2012). Toyota by Toyota: Reflections from the Inside Leaders on the Techniques That Revolutionized the Industry. CRC Press. https://doi.org/10.1201/b11902

Oker, F., \& Adiguzel, H. (2016). Time-Driven Activity-Based costing an implementation in a manufacturing company. Journal of Corporate Accounting \& Finance, 27(3), 39-56. https://doi.org/10.1002/jcaf.20646

Pawłyszyn I. (2017). Time-driven activity based costing as a basis for undertaking LEAN activities. LogForum, 13(2), 135-149. http://dx.doi.org/10.17270/J.LOG.2017.2.2

Pickering, M. E., \& Byrnes, V. A. (2016). The changing role of management accountants in a LEAN enterprise - from 'bean counter' to delivering customer value. Cost Management, 30(1), 38-47.

Raeesi, R., \& Amini, A. (2013). Developing a Grey Activity Based Costing (G-ABC) method to capture the inherent uncertainty in identifying cost drivers' consumption rates. Academy of Accounting and Financial Studies Journal, $17(2), 41-56$

Rauner, M. S., Heidenberger, K., \& Pesendorfer, E. M. (2005). Model-based evaluation of diabetic foot prevention strategies in Austria. Health care management science, 8(4), 253-265. https://doi.org/10.1007/s10729-005-4136-6

Santana, A., Afonso, P., Zanin, A., \& Wernke, R. (2017). Costing models for capacity optimization in Industry 4.0: Tradeoff between used capacity and operational efficiency. Procedia Manufacturing, 13, 1183-1190. https://doi.org/10. 1016/j.promfg.2017.09.193

Siguenza-Guzman, L., Van den Abbeele, A., \& Cattrysee, D. (2014). Time driven activity based costing system for cataloguing process: a case study. Liber Quarterly, 23(3), 160-186. https://doi.org/10.18352/lq.8558

Tanis, V. N., \& Ozyapici, H. (2012). The measurement and management of unused capacity in a Time Driven Activity Based costing system. Journal of Applied Management Accounting Research, 10(2), 43-54.

Terzioglu, B., \& Chan, E. S. (2013). Toward Understanding the Complexities of Service Costing: A Review of Theory and Practice. Journal of Applied Management Accounting Research, 11(2), 29-42.

Wnuk-Pel, T. (2018). Management Accounting Practices in Support of Lean Management Strategy in Service Organizations. Inzinerine Ekonomika-Engineering Economics, 29(5), 559-570. https://doi.org/10.5755/j01.ee. 29.5.20763

The article has been reviewed.

Received in July 2019; accepted in February 2020. 